\title{
Anesthesia Technique
}

André P. Boezaart MBChB MPraxMed FFA(SA) $\operatorname{MMed}($ Anacsth)*

Joe F. de Beer MBChB MMed(ORTH), Christa du Toit MBChB MMcd(Anacsth), Karin van Rooyen $M B C h B$

\section{A new technique of continuous interscalene nerve block}

Purpose: To describes a technique of indwelling interscalene catheter placement and to evaluate its complications. Methods: One hundred and twenty patients undergoing major shoulder surgery received interscalene nerve block (ISNB) and were studied in three groups. Group I ISNB using Winnie's technique; group 2 by Winnie's technique with nerve stimulator and group 3 by epidural needle and catheter technique with nerve stimulator. All patients received $20 \mathrm{~mL}$ bupivacaine $0.5 \%$ and group 3 patients received an additional bupivacaine $0.25 \%$ infusion. Diaphragmatic movements were measured sonographically on emergence from anesthesia. Complications were noted. A visual analogue scale (0-10) was used to assess pain four hours postoperatively.

Results: Mean ipsilateral diaphragmatic movements were $4 \pm 8,14 \pm 11$ and $18 \pm 8 \mathrm{~mm}$ (mean $\pm S D$ ) in groups 1,2 and 3 respectively. This was less than contralateral movements in all three groups $(P<0.05)$. None of the patients in groups 2 and 3 reported postoperative pain. The block failed in 10\% of group I patients. Complete ipsilateral phrenic nerve block occurred in $85 \%$ of the patients in group 1, 35\% of group 2 and $20 \%$ of group $3(P<0.05)$. Ipsilateral recurrent laryngeal nerve paralysis occurred in $20 \%$ of the patients in group I, $5 \%$ of group 2 and in none of the patients in group $3(P<0.05)$. Horner's syndrome was noted in group 1 (30\%), group 2 (12\%) but not in group 3 . None of the catheters in group 3 patients dislodged after an average use of $2.8 \pm 2.1$ days.

Conclusions: Indwelling catheter placement into the brachial plexus sheath as described in this communication was effective and associated with few complications.

Objectif : Décrire une technique de mise en place d'une sonde interscalène à demeure et évaluer ses inconvénients.

Méthode : Cent vingt patients admis pour une chirurgie majeure de l'épaule ont reçu un blocage nerveux interscalène (BNIS) et ont été répartis en trois groupes d'étude. Dans le ler groupe, on a utilisé la technique de Winnie ; dans le $2^{\mathrm{e}}$, la technique et un neurostimulateur; dans le $3^{\mathrm{e}}$, une aiguille péridurale et la technique avec stimulateur. Tous ont reçu $20 \mathrm{ml}$ de bupivacaine $0,5 \%$ et ceux du groupe 3 , une perfusion supplémentaire de bupivacaïne $0,25 \%$. Au réveil, on a mesuré par échographie les mouvements diaphragmatiques et, quatre heures après l'intervention, on a noté les complications et évalué la douleur à l'aide de l'échelle visuelle analogue (0-10).

Résultats : Les mouvements homolatéraux du diaphragme ont été de $4 \pm 8,14 \pm 1 \mid$ et de $18 \pm 8 \mathrm{~mm}$ (moyenne \pm écart-type) dans les groupes 1,2 et 3 respectivement et plus faibles que les mouvements controlatéraux dans les trois groupes $(P<0,05)$. Aucun patient des groupes 2 et 3 n'ont eu de douleur postopératoire. Le bloc a échoué chez $10 \%$ des patients du groupe I. Le bloc complet du nerf phrénique homolatéral est survenu chez $85 \%$ des patients du groupe I, $35 \%$ du groupe 2 et $20 \%$ du groupe $3(P<0,05)$; la paralysie récurrente du nerf laryngé homolatéral, chez $20 \%$ des patients du groupe 1, $5 \%$ du groupe 2 , mais chez aucun patient du groupe $3(P<0,05)$. On a noté le syndrome de Horner dans les groupes $1(30 \%)$ et $2(12 \%)$, mais non dans le groupe 3 . Aucune sonde du groupe 3 ne s'est déplacée après un usage moyen de $2,8 \pm 2,1$ jours. Conclusion : La mise en place d'une sonde à demeure dans la gaine du plexus brachial, telle qu'on la décrite ici, a été efficace et a présenté peu de complications.

From the Cape Shoulder Institute, Cape Town and the Department of Anesthesiology, ${ }^{*}$ University of Stellenbosch, Wcstern Cape, South Africa.

Address correspondence to: Dr A.P. Boezaart, Cape Shoulder Instinute, P.O. Box 6023, Main Strect Paarl 7622, South Africa.

Phonc: 27-21-8727799; Fax: 27-21-8631945; E-mail: apbzrt@iafrica.com

Accepted for publication October 21,1998 
INGLE bolus injections of local anesthetic into the interscalene groove as described by Winnie in $1970,{ }^{1}$ has been used extensively and with good results for surgery of the shoulder. Since the introduction of the nerve stimulator to assist in the placement of nerve blocks by Meyer in $1981,{ }^{2}$ the success rate of nerve blocks in general has improved ${ }^{2}$ and there is a perception that the complication rate had decreased, but this has not been proved.

To overcome the relatively short duration of action of local anesthetic after single bolus injection into the interscalene groove, various techniques for continuous interscalene nerve block (CISNB) have been attempted with differing success rates. The earliest was that of Ansbro in $1946 .{ }^{3}$ Later authors ${ }^{4}$ described methods of placing epidural catheters in the vicinity of the dorsal root of the brachial plexus but these efforts were not always successful and no method has enjoyed universal acceptance. This is probably because these techniques often failed to provide optimal analgesia and because of the high incidence of early postoperative catheter dislodgment. ${ }^{5}$

We describe a technique to place a catheter (not only the needle for feeding the catheter) into the interscalene brachial plexus sheath accurately and a method to secure the catheter. A further purpose of this study was to evaluate abnormal diaphragmatic function and other complications following this technique objectively, and to compare this with two existing techniques of interscalene nerve block (ISNB): 1) standard ISNB making use of anatomical landmarks without the aid of a nerve stimulator as described by Winnie $^{1}$ and, 2) ISNB making use of Winnie's technique and using a nerve stimulator to locate the brachial plexus. ${ }^{2}$ Typical indications for CISNB would be for the management of postoperative pain following rotator cuff repair and shoulder arthroplasty, and to aid in the postoperative physiotherapy management of adhesive capsulitis after arthroscopic capsulotomy.

\section{Methods}

This study was approved by our institutional ethical committee and written informed consent was obtained from 120 adult, ASA I or II patients presenting for major shoulder surgery. The 73 female and 47 male patients (mean age of $56 \pm 14 \mathrm{yr}$, mean $\pm S D$ ) were divided in three equal groups by random allocation (card draw). Patients with specific indications or contra-indications for a specific type of nerve block were excluded from the study. The 40 patients allocated to group 1 received a standard ISNB without the aid of a nerve stimulator ${ }^{1}$ as described by Winnie. Those in group 2 received a nerve stimulator
(Stimuplex $S ®, B$ Braun Melsungen, München, Germany) assisted single bolus ISNB, and the 40 patients in group 3 underwent nerve stimulator assisted placement of a catheter into the brachial plexus sheath. A sheathed short-beveled 20 gauge needle (Stimuplex®, B Braun, München, Germany) was used for the nerve blocks in group 1 and 2 patients. All nerve blocks were performed after the induction of general anesthesia.

\section{Placement of catheter into interscalene brachial plexus sheath}

The anterior and middle scalene muscles are posterior to the clavicular head of the sternocleidomastoid muscle. ${ }^{1}$ The fascia covering both scalene muscles is derived from the paravertebral fascia, which splits to invest these muscles and then fuses again at their lateral margins to form an enclosed interscalene space. The interscalene groove is frequently crossed by the external jugular vein, which provides an additional landmark. The roots of the brachial plexus descend between the posterior fascia of the anterior scalene muscle and the anterior fascia of the middle scalene muscle. The phrenic nerve is situated on the belly of the anterior scalene muscle.

For continuous ISNB (CISNB) an unsheathed 17 G Tuohy needle is used (Continuous Epidural Needle ${ }^{\circledR}$, Arrow, Reading, PA, USA) with a catheter (Arrow Theracath $®$, Arrow, Reading, PA, USA) an inner steel spring reinforcement, steel stylet and an unsheathed metal tip. An anesthetic nerve stimulator (Digistim 3 plus ${ }^{\circledR}$, Neuro Technology Inc., Houston, Texas) was used with the active lead (negative lead) clipped to the shaft of the needle and the ground lead (positive lead) attached to the patient with a standard skin ECG electrode. The stimulating current was set as described by Bösenberg, ${ }^{6}$ so that the impulses could just be felt by the operator when the two poles were held between the forefinger and thumb - approximately $1.5-2.5 \mathrm{~mA}$.

The patient was positioned in the dorsal recumbent position with the head in slight extension and turned somewhat to the opposite side. An assistant applied light traction on the arm with the elbow flexed. The interscalene groove can usually easily be palpated in this position. The posterior edge of the clavicular head of the sternocleidomastoid muscle is palpated with the palpating fingers lateral to the muscle to identify the interscalene groove. The external jugular vein is usually in the way and provides a useful landmark. Needle entry should be anterior or posterior to the vein. Another constant landmark is the interscalene groove which is approximately $3 \mathrm{~cm}$ lateral to the most 


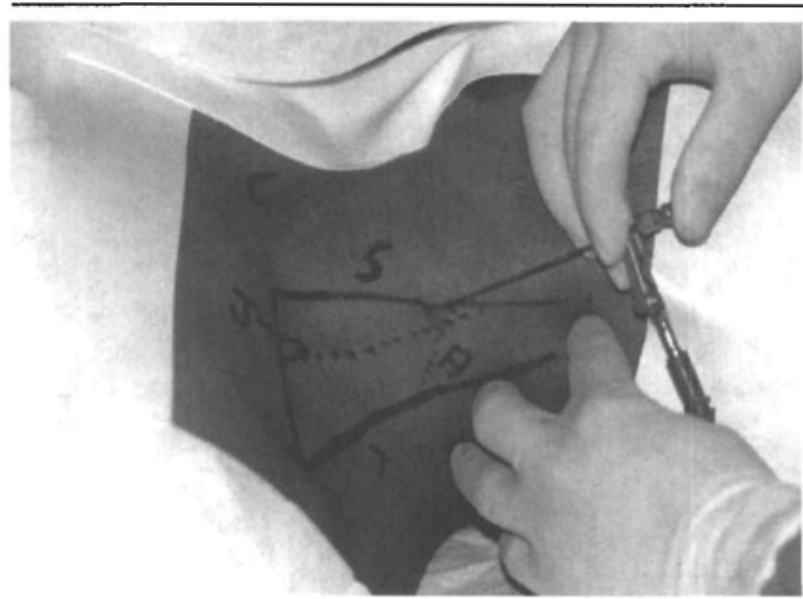

FIGURE 1 Skin entry. The needle is directed caudal and parallel to the vertebrae. The entry point is just inferior to the accessory nerve and just posterior to the posterior border of the clavicular head of the sternocleidomastoid muscle approximately midway berween the mastoid and the clavicle.

$A=$ Accessory nerve

$C=$ Suprasternal notch

$\mathrm{J}=$ External jugular vein

$S=$ Stcrnoclcidomastoid musclc - clavicular hcad

$\mathrm{I}$ = Trapczius muscle

prominent portion of the belly of the sternocleidomastoid muscle at the level of the cricoid cartilage. ${ }^{7}$

Using the technique described by Winnie, ${ }^{1}$ the needle is inserted at the level of the cricoid cartilage $\left(\mathrm{C}_{6}\right.$ level) and directed perpendicular to the skin in all planes. To place the catheter for the continuous ISNB technique, the needle enters the skin approximately halfway between the mastoid and the clavicle, posterior to the posterior border of the clavicular head of the sternocleidomastoid muscle. The needle is directed caudally and parallel to the vertebre (Figure 1). This point is just inferior to the accessory nerve (which can usually be identified by percutaneous stimulation using the active lead of the nerve stimulator) and is just posterior to the anterior border of the posterior triangle of the neck. The interscalene groove can, in most cases, be palpated in this position. All these nerves can be identified by transcutaneous stimulation. The accessory nerve supplies the trapezius muscle and, when srimulated, causes elevation of the shoulder girdle. The nerves to the levator scapula and rhomboid muscles also cause twitching and movement of the shoulder girdle when stimulated. The phrenic nerve, situated on the belly of the anterior scalene muscle, may also be encountered causing unmistakable twitching of the ipsilateral diaphragm and a typical capnograph pattern. These

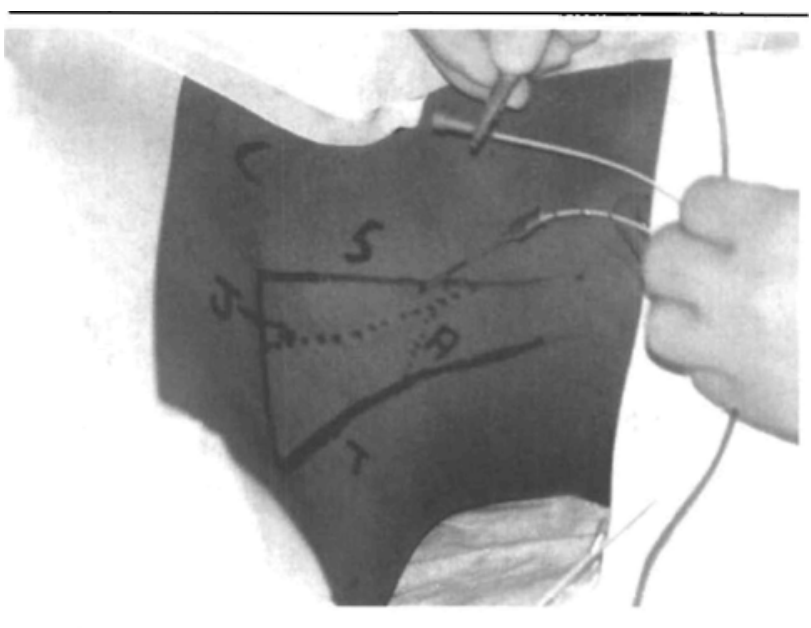

FIGURE 2 The catheter is fed to a point just past the tip of the needle. The active lead of the nerve stimulator is clipped to the stylet of the catheter.

nerves should be avoided by redirection and/or reinsertion of the needle as stimulation may provide false impressions of correct needle placement that will lead to block failure or phrenic nerve paralysis if local anesthetic is injected at this stage. When the brachial plexus is encountered, definite and unmistakable twitching should be observed in the biceps muscle. This is why the elbow is slightly flexed during the procedure. If the phrenic nerve is accidentally stimulated the needle is pulled back slightly and the point is directed slightly posteriorly until the brachial plexus is encountered. As the needle is advanced further a distinct "pop" or give can usually be felt followed by an increase of the intensity of the biceps and deltoid muscle twitching. This occurs when the fascial sheath of the brachial plexus is penetrated and the tip of the needle is now in direct contact with the brachial plexus.

The inner stylet of the needle is removed and the Theracath $\otimes$ is fed just past the tip of the needle, far enough so that the metal tip of the catheter does not make contact with the needle. The active lead of the nerve stimulator is clipped to the stylet of the catheter (Figure 2). The output of the nerve stimulator can be decreased (to approximately $0.5-1.0 \mathrm{~mA}$ ) as the muscle twitching will increase because all the current is now concentrated in the unsheathed tip of the catheter.

Advancement of the catheter down the brachial plexus sheath should not result in decrease of the twitching in the biceps muscle. Frequently, though, the muscle twitching does decrease in which case the needle and catheter complex are pulled back slightly until maximal twitching is again observed. The catheter is 


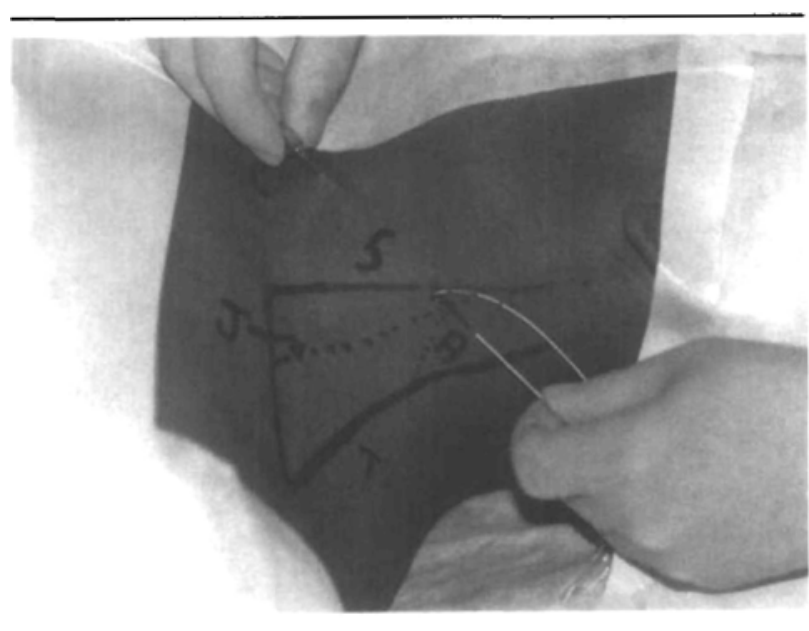

FIGURE 3 Catheter fixation. To fix the catheter securely the Tuohy needle is inserted just above the suprasternal notch (c) and directed subcutaneously superolaterally to exit at the entry point of the catheter. The proximal end of the catheter is fed through the necdle.

then advanced again and the process is repeated until maximal twitching is observed during catheter advancement. The tip of the catheter can now be manipulated and placed exactly where required. The catheter frcquently fails to be fed with ease beyond the coracoid process. It should not be forced further as this may lead to nerve damage. The needle and wire stylet are then removed and the catheter is fixed securely.

\section{SECURE FIXATION OF THE CATHETER}

Indwelling interscalene catheters are often dislodged. After placement of the catheter, the Tuohy needle is inserted subcutaneously just above the suprasternal notch and directed superolaterally, avoiding vascular structures, and directed towards the point of entry of the catheter (Figure 3). The needle is advanced to exit through the same orifice in the skin as the catheter and just next to the catheter. The proximal end of the catheter is fed through the needle and the needle is removed so that the catheter is tunncled subcutaneously (Figure 4). Kinking of the catheter should be avoided as the elbow formed by the catheter disappears under the skin. The catheter is then covered with a transparent dressing. (This CISNB can be done with the patient under general anesthesia, under propofol conscious sedation or following local infiltration of the area with local anesthetic agent).

General anesthesia was standard for all patients in the present study and was induced with $2 \mathrm{mg} \cdot \mathrm{kg}^{-1}$ propofol followed by $100 \mu \mathrm{g}$ fentanyl $i v$. A laryngeal mask airway

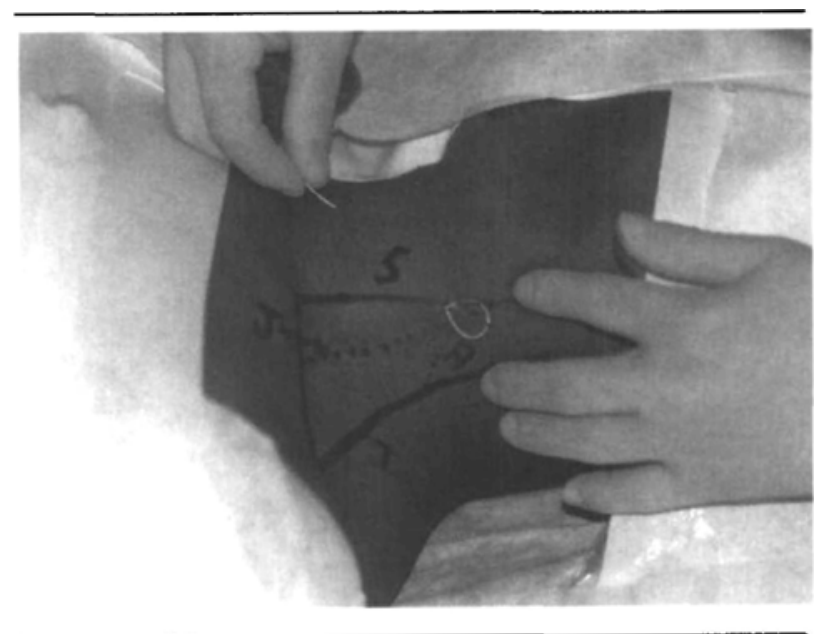

FIGURE 4 The needle is removed to facilitate subcutancous tunneling of the catheter

was then placed and the lungs were slightly hyperventilated to an $\mathrm{P}_{\mathrm{ET}} \mathrm{CO}_{2}$ of approximately $4 \mathrm{kPa}$ to inhibit attempts at spontaneous ventilation. No muscle relaxants were used and anesthesia was maintained with sevoflurane in a $\mathrm{N}_{2} \mathrm{O}: \mathrm{O}_{2} 50 \%$ mixture. All patients received $20 \mathrm{~mL}$ bupivacaine $0.5 \%$ as a bolus injection into the interscalene brachial plexus sheath after the induction of general anesthesia. Patients in group 3 received additional bupivacaine $0.25 \%$ as a continuous infusion via the catheter placed into the brachial plexus sheath at an initial infusion rate of $10 \mathrm{~mL} \cdot \mathrm{hr}^{-1}$ during the postoperative period. The infusion rate was later adjusted if necessary to meet the analgesic requirements of the patients.

After emergence from anesthesia, patients were positioned in a $20^{\circ}$ head-up position and diaphragmatic movements measured sonographically by an experienced sonographist who was blinded to the ISNB technique. The diaphragmatic movements were measured bilaterally from full expiration to full inspiration.

Pain was assessed four hours postoperatively on a visual analog scale (VAS) from 0 - 10. Recurrent laryngeal nerve function was assumed to be affected if the patient experienced hoarseness after excluding other possible causes for hoarseness, e.g. trauma caused by the laryngeal mask airway. Blockade of the stellate ganglion was recorded if ipsilateral Horner's syndrome was present.

Data were analyzed with a commercially available statistical program (MINITAB: MINITAB Inc., State 
College PA 16801-3008, USA). Data on "Complete phrenic nerve block", "Recurrent laryngeal nerve block" and "Horner's syndrome" were summarized in $3 \times 2$ contingency tables according to the two response categories "yes" and "no". A global test of equality of the groups with respect to probability of "yes" response was performed by calculation of the chi-squared statistic. In cases of "Recurrent laryngeal nerve block" and "Horner's syndrome", some of the cell frequencies were small, so the results of the chisquared test were confirmed by an exact procedure. Pair-wise comparisons of the groups were carried out by extracting the relevant $2 \times 2$ contingency tables from the $3 \times 2$ tables and performing chi-squared or exact tests of association as appropriate.

Comparisons of mean diaphragmatic movement of the groups were made using one way analysis of variance. Examination of the data showed that the assumptions of normality and homoscedasticity were not strictly satisfied. Consequently, Kruskal-Wallis and sign tests were performed to check the conclusions suggested by the F-tests. A $P$ value $<0.05$ was accepted as indicative of a statistically significant difference.

\section{Results}

Results are summarized in the Table. Mean ipsilateral diaphragmatic movements were $4 \pm 8,14 \pm 11$ and 18 $\pm 8 \mathrm{~mm}$ (mean $\pm \mathrm{SD})$ in groups 1,2 and 3 respectively. This was less than contralateral movements in all three groups $(P<0.05)$. None of the patients in groups 2 and 3 reported postoperative pain. The block failed in four patients $(10 \%)$ in group 1. Complete ipsilateral phrenic nerve block occurred in $85 \%$ of the patients in group 1 , in $35 \%$ of group 2 and in $20 \%$ of group $3(P<0.05)$. Ipsilateral recurrent laryngeal nerve paralysis occurred in $20 \%$ of the patients in group $1,5 \%$ in group 2 and in none of the patients in group $3(P<0.05)$. Horner's syndrome was noted in group $1(30 \%)$, group $2(12 \%)$ but not in group 3. No patient complained of pain or tenderness at the site of the injection or the site of catheter entry and no inflammation or sepsis were observed. All the catheters placed in group 3 patients remained in place for the duration of treatment: no catheter became dislodged. The average time that the catheters were used was $2.8 \pm 2.1$ days (range 1-6 days). Complete or incomplete diaphragmatic paralysis was asymptomatic but, if complete paralysis occurred together with recurrent laryngeal nerve paralysis, the patients experienced respiratory distress. This occurred in 13 patients in group 1 and in five patients in group 2 . Oxygen administration and reassurance satisfactorily managed the problem. None of the patients suffered any ill effects due to this dual block and diaphragmatic function returned to normal in all patients within three hours postoperatively.

\section{Discussion}

Postoperative analgesia was excellent in all three groups and this is consistent with that of other authors. ${ }^{8}$ Patient acceptance of the technique was not evaluated by the current study but interscalene nerve block is generally well accepted. ${ }^{8}$ A low failure rate of ISNB has been reported from the outset ${ }^{1,9}$ and this has probably contributed to the popularity of the technique. Winnie, et al. ${ }^{9}$ reported a $97 \%$ success rate.

Continuous ISNB, however, has been received with less enthusiasm and was less successful. In a study of 126 patients over two years Koh \& Lim found effective postoperative analgesia in only $70 \%$ of patients following hand surgery although they regarded the technique as effective and easy to implement. ${ }^{5}$ The chief reason for failure of continuous ISNB in the latter study was catheter dislodgment. In another study, infusion of local anesthetic was interrupted in six of 24 patients due to catheter failure. ${ }^{4}$ In addition, nine of the remaining 18 patients needed additional analgesia. The authors of this study ${ }^{4}$ advocated suturing the catheter to the skin to prevent displacement, but this was not very effective. The high failure rate in patients in whom catheter dislodgment did not occur was probably due to inaccurate catheter placement. Accurate placement with the assistance of a nerve stimulator in the present study seemed to solve this problem since no patient required additional analgesia. Nerve stimulation via the catheter as an aid to accurate placement is only possible if a catheter which can conduct a current to its tip, such as the Theracath ${ }^{\circledR}$, is used.

The method of fixing the catheter was successful in all cases since no displacement of catheters was recorded. Pain at the insertion site, a frequent complication reported by Koh \& Lim, ${ }^{5}$ was not encountered. The absence of pain at the site of the catheter insertion can probably be attributed to the fact that the tunneling of the catheter prevented skin and subcutaneous inflammation, and the secure fixation prevented movement which may also have prevented continuous irritation.

Urmey and colleagues ${ }^{10}$ reported a $100 \%$ incidence of hemidiaphragmatic paralysis associated with ISNB. They used $34-52 \mathrm{~mL}$ mepivacaine $1.5 \%$ for the ISNB and made use of paresthesia to locate the brachial plexus in the interscalene groove. Later Urmey and Gloeggler ${ }^{11}$ demonstrated that using the same technique, but only $20 \mathrm{~mL}$ of local anesthetic, did not reduce the incidence of diaphragmatic paresis. Others have reported similar findings ${ }^{12}$ when using the 
TABLE Complications of interscalene nerve blocks

\begin{tabular}{|c|c|c|c|}
\hline & $\begin{array}{l}\text { Group } 1 \\
(\text { Winniel) }\end{array}$ & $\begin{array}{l}\text { Group } 2 \\
\text { (Stimuplex@) }\end{array}$ & $\begin{array}{l}\text { Group } 3 \\
\text { (Continuous) }\end{array}$ \\
\hline Number of patients & 40 & 40 & 40 \\
\hline Postoperative surgical pain (VAS $0-10$ ) & $0.67 \pm 1.17$ & $0^{*}$ & $0^{*}$ \\
\hline Failed blocks & $4(10 \%)$ & $0^{*}$ & $0^{*}$ \\
\hline Complete phrenic nerve block & $34(85 \%)$ & $14(35 \%)^{\star}$ & $8(20 \%)^{*}$ \\
\hline Recurrent laryngeal nerve block & $8(20 \%)$ & $2(5 \%)$ & $0(0 \%)^{\star} \dagger$ \\
\hline Horner's syndrome & $12(30 \%)$ & $4(10 \%)^{\star}$ & $0(0 \%)^{\star} \dagger$ \\
\hline Ipsilateral diaphragmatic movement (mm) & $4 \pm 8 \mathrm{~mm} \ddagger$ & $14 \pm 11 \mathrm{~mm}^{*} \ddagger$ & $18 \pm 8 \mathrm{~mm}{ }^{*} \ddagger$ \\
\hline Contralateral diaphragmatic movement (mm) & $33 \pm 4 \mathrm{~mm}$ & $32 \pm 7 \mathrm{~mm}$ & $31 \pm 8 \mathrm{~mm}$ \\
\hline
\end{tabular}

* Different from group $1(P<0.05)$

$\dagger$ Different from groups 1 and $2(P<0.05)$

$¥$ Different from contralateral side $(P<0.05)$

VAS $=$ Visual analogue scale for pain

Winnie technique ${ }^{1}$ without a nerve stimulator. This is consistent with the findings in group 1 patients in the current study where $85 \%$ of patients had ipsilateral diaphragmatic paralysis. Pere and colleagues ${ }^{13}$ also demonstrated ipsilateral hemidiaphragmatic paresis following continuous ISNB in 10 of 10 patients studied three hours after the initial ISNB. The current study does not support this as only $20 \%$ of the patients in group 3 developed ipsilateral phrenic nerve paresis. None of the patients in the study of Pere $e t$ al. ${ }^{13}$ suffered dyspnea in spite of abnormal respiratory functions. The use of a nerve stimulator to identify the brachial plexus in the current study considerably reduced the incidence of complete hemidiaphragmatic paralysis by facilitating more accurate placement of the needle into the brachial plexus sheath.

The question arising from the current study is why the diaphragmatic movements decreased less in group 3 than in group 2 which was also less than in group 1. The ipsilateral diaphragmatic movements were less in all three groups than in the contralateral diaphragms. It can be speculated that, with the aid of a nerve stimulator (group 2), the local anesthetic agent was injected to a greater extent into the brachial plexus sheath thus sparing the phrenic nerve which is situated outside the sheath on the belly of the anterior scalene muscle. Therefore, a lower volume of local anesthetic came into contact with the phrenic nerve than during injection without the aid of a nerve stimulator. Also, with distal placement of the catheter tip inside the brachial plexus sheath (group 3), the risk should be minimized. Retrograde flow of local anesthetic agent could account for the ipsilateral diaphragmatic paresis. The same argument can be offered to explain the occurrence of Horner's syndrome and recurrent laryngeal nerve paresis. Any of the complications described above, when occurring separately, did not seem to cause respiratory distress. If, however, recurrent laryngeal nerve paresis and phrenic nerve paresis occurred simultaneously, the patients suffered respiratory distress. No explanation for this can be offered. It may be speculated that aspiration of small amounts of saliva together with the inability to cough effectively due to paralysis of both these nerves, may be responsible for the sensation of respiratory distress. However, the distress was not quantified in terms of ventilatory function or blood gas analysis. The respiratory distress was easily managed with oxygen and reassurance. It must be recognized that we studied healthy patients. In the presence of abnormal diaphragmatic function and/or lung dysfunction this dual block may lead to severe respiratory distress.

It is concluded that the method described in this study for providing continuous ISNB was effective and associated with a low risk of phrenic and recurrent laryngeal nerve paresis and Horner's syndrome. Although simultaneous recurrent laryngeal nerve and phrenic nerve paresis did not occur in the continuous ISNB group and only in the other two groups, all techniques of ISNB, including CISNB, should be used with caution in patients with cardiovascular and pulmonary disease. This study demonstrated a high incidence of complications in the absence of nerve stimulation and thus it is recommended that a nerve stimulator be used for interscalene nerve block.

\section{References}

1 Winnie $A P$. Interscalene brachial plexus block. Anesth Analg 1970; 49: 455-66.

2 Meyer J. A new nerve-stimulator "Neurostim LA". (German) Regional- Anaesthesie 1981; 4: 34-5.

3 Ansbro FP. A method of continuous brachial plexus block. Am J Surg 1946; 121: 716-22. 
4 Tuominen $M$, Haasio J, Hekali R, Rosenberg $P H$.

Continuous interscalene brachial plexus block: clinical efficacy, technical problems and bupivacaine plasma concentrations. Acta Anaesthesiol Scand 1989; 33: 84-8.

$5 \mathrm{Koh} D L H, \operatorname{Lim} B H$. Postoperative continuous interscalene brachial plexus blockade for hand surgery. Ann Acad Med Singapore 1995; 24(Suppl): 3-7.

6 Bösenberg $A T$. Lower limb nerve blocks in children using unsheathed needles and a nerve stimulator. Anaesthesia 1995; 50: 206-10.

7 Brown AR, Broccoli E. An aid to the performance of interscalene blocks. Anesthesiology 1992; 76: 869-70.

8 Tetzlaff JE, Yoon HJ, Brems J. Patient acceptance of interscalene block for shoulder surgery. Reg Anesth 1993; 18: 30-3.

9 Winnie AP, Ramamurthy $S$, Durrani $Z$, Radonjic $R$. Interscalene cervical plexus block: a single-injection technic. Anesth Analg 1975; 54: 370-5.

10 Borgeat A, Schäppi B, Biasca N, Gerber C. Patient-controlled analgesia after major shoulder surgery. Patientcontrolled interscalene analgesia versus patientcontrolled analgesia. Anesthesiology 1997; 87: 1343-7.

11 Urmey WF, Talts $K H$, Sharrock NE. One hundred percent incidence of hemidiaphragmatic paresis associated with interscalene brachial plexus anesthesia as diagnosed by ultrasonography. Anesth Analg 1991; 72: 498-503.

12 Urmey WF, Gloeggler PJ. Pulmonary function changes during interscalene brachial plexus block: effects of decreasing local anesthetic injection volume. Reg Anesth 1993; 18: 244-9.

13 Fujimura $N$, Namba $H$, Tsunoda $K$, et al. Effect of hemidiaphragmatic paresis caused by interscalene brachial plexus block on breathing patterns, chest wall mechanics, and arterial blood gases. Anesth Analg 1995; 81: 962-6.

14 Pere $P$, Pitkänen $M$, Rosenberg $P H$, et al. Effect of continuous interscalene brachial plexus block on diaphragm motion and on ventilatory function. Acta Anaesthesiol Scand 1992; 36: 53-7. 